\title{
The Adult Learning Open University Determinants (ALOUD) study: Biological and psychological factors associated with learning performance in adult distance education
}

Citation for published version (APA):

Neroni, J., Gijselaers, J., Kirschner, P. A., \& De Groot, R. (2015). The Adult Learning Open University

Determinants (ALOUD) study: Biological and psychological factors associated with learning performance in adult distance education. British Journal of Educational Technology, 46(5), 953-960.

https://doi.org/10.1111/bjet.12288

DOI:

10.1111/bjet.12288

Document status and date:

Published: 01/09/2015

Document Version:

Peer reviewed version

Document license:

CC BY-NC-ND

Please check the document version of this publication:

- A submitted manuscript is the version of the article upon submission and before peer-review. There can be important differences between the submitted version and the official published version of record. People interested in the research are advised to contact the author for the final version of the publication, or visit the DOI to the publisher's website.

- The final author version and the galley proof are versions of the publication after peer review.

- The final published version features the final layout of the paper including the volume, issue and page numbers.

Link to publication

\section{General rights}

Copyright and moral rights for the publications made accessible in the public portal are retained by the authors and/or other copyright owners and it is a condition of accessing publications that users recognise and abide by the legal requirements associated with these rights.

- Users may download and print one copy of any publication from the public portal for the purpose of private study or research.

- You may not further distribute the material or use it for any profit-making activity or commercial gain

- You may freely distribute the URL identifying the publication in the public portal.

If the publication is distributed under the terms of Article 25fa of the Dutch Copyright Act, indicated by the "Taverne" license above, please follow below link for the End User Agreement:

https://www.ou.nl/taverne-agreement

Take down policy

If you believe that this document breaches copyright please contact us at:

pure-support@ou.nl

providing details and we will investigate your claim.

Downloaded from https://research.ou.nl/ on date: 26 Apr. 2023 
The Adult Learning Open University Determinants (ALOUD) study: Biological and psychological factors associated with learning performance in adult distance education

Joyce Neroni ${ }^{1}$, Hieronymus J.M. Gijselaers ${ }^{1}$, Renate H.M. de Groot ${ }^{1}$, Paul A. Kirschner ${ }^{1}$ Open University of the Netherlands

\section{Author Note}

${ }^{1}$ Welten Institute - Research Centre for Learning, Teaching and Technology, Open University of the Netherlands, Heerlen, the Netherlands.

Correspondence concerning this article should be addressed to Joyce Neroni, Welten Institute, Open University of the Netherlands, P.O. Box 2960, 6401 DL Heerlen, the Netherlands. E-mail: joyce.neroni@ou.nl

This is the peer reviewed version of the following article: [Neroni, J., Gijselaers, $H$. J.M., Kirschner, P. A. and de Groot, R. H.M. (2015), The Adult Learning Open University Determinants (ALOUD) study: Biological and psychological factors associated with learning performance in adult distance education. British Journal of Educational Technology, 46: 953-960. doi:10.1111/bjet.12288], which has been published in final form at [http://doi.org/10.1111/bjet.12288]. This article may be used for non-commercial purposes in accordance with Wiley Terms and Conditions for Self-Archiving. 


\begin{abstract}
Learning is crucial for everyone. The association between biological (e.g., sleep, nutrition) and psychological factors (e.g., test anxiety, goal orientation) and learning performance has been well established for children, adolescents, and college students in traditional education. Evidence for these associations for adult distance students is lacking however. The Adult Learning Open University Determinants (ALOUD) study is the first to identify the determinants of learning performance within adult distance education. Over the course of one year all new students $(\mathrm{N}=4945)$ of the Open University of the Netherlands (OUNL) were approached. At baseline, 2040 students fully participated in this observational longitudinal study by filling out an online questionnaire and performing cognitive tests. At the 7 and 14 months follow-up participants filled out a second and third questionnaire respectively, and data was given by the exam registration office to measure learning performance at these times. The ALOUD study might result in tailor-made educational innovations for adults participating in distance education and, finally, a more successful distance education student population.
\end{abstract}

Key words: determinants, learning performance, distance education 


\section{The dataset}

\section{Location and DOI}

Currently the data is saved at a local server as data collection is not finished yet. Soon, data will be stored in DANS EASY (https://easy.dans.knaw.nl/ui/home).

\section{Creator}

Renate H.M. de Groot, Paul A. Kirschner, Hieronymus J.M. Gijselaers, Joyce Neroni.

\section{Date}

Baseline data was collected between 28 August 2012 and 6 October 2013, first follow-up data between 19 March 2013 and 29 March 2014, and second follow-up data between 15 October 2013 and the end of November 2014.

\section{Format}

Different formats are possible, e.g., SPSS-file, Excel-file, R data file.

\section{Restrictions to use (if any)}

As the research papers on the ALOUD study are still in progress, data will be revealed only after our determination whether the inquiry is relevant and is not competing with our own research questions. For further information or admission to the data, please contact us via the contact information given at author note. 


\section{Introduction}

Learning is crucial for people of all ages. Though much is known about biological and psychological determinants of learning for children, adolescents, and college students within traditional education, relatively little is known about determinants of learning performance of adults in distance education. This apparent lack of knowledge is the basis of the Adult Learning Open University Determinants (ALOUD) study.

Learning has been an area of interest for many researchers. Within children, adolescents, and college students, the association between biological and psychological factors on the one hand and learning performance on the other has already been extensively studied (e.g., Howie \& Pate, 2012; Richardson, Abraham, \& Bond, 2012; Wigfield \& Cambria, 2010). Although studies are mainly focused on the young, learning is not solely carried out by children; it is a process which is actively sought out by people of all ages.

In adult education, a field which is expanding in both importance as well as prevalence, it is not clear how these factors are associated with learning performance. This population is not only unique on the age dimension, but also with respect to the time-factor. In this age category, people often try to combine jobs, families, and hobbies which in turn effects both the available time for study and their biological and psychological states.

ALOUD is the first study to identify the biological and psychological determinants of learning performance within adult distance education (see Figure 1). It will yield new insights in determinants for learning in lifelong perspective and in the change in time within the individual. Based upon the results from this observational study, effective innovations can be developed to optimize current learning programs. This will result in tailor-made lifelong learning programs.

[Figure 1 about here] 


\section{Research method}

\section{Design}

The study is an observational longitudinal study in adult distance students of the Open University of the Netherlands (OUNL) using an online questionnaire and cognitive tests.

\section{Context}

OUNL has seven educational bachelor and master programs: Law, Management Science, Computer Science, Environmental Science, Cultural Science, Learning Sciences, and Psychology, which together contain approximately 300 different courses. No prior education is required to study at the OUNL (i.e., open admission). The only requirement is a minimum age of 18 years. Students can be enrolled in one or more individual courses at once, or in a full-length degree program. They can choose from nearly 300 courses. In most courses, Dutch is the primary language, in some courses English. A course consists of one or more modules, and each module stands for 4.3 European Credits (ECs); 120 hours of studying. Students can begin a course any time they want and they can study at their own pace. Each course ends with an examination, which can be a written examination with open and/or closed questions, a computer based examination, an oral examination, or a final project or paper. In general, students have three attempts to pass for an exam and they have to finish the course within 14 months from the time they started the course. Some courses have exams on fixed dates, whereas in other courses the student determines the date of the exam.

\section{Procedure}

Baseline. Students who signed up for their first course(s) at the OUNL between 6 August 2012 and 5 August 2013 automatically received an email invitation 14-21 days after successful registration. Before they were able to start with the questionnaire participants were 
obliged to tick a box in order to agree to an informed consent form. At the end of the questionnaire there was a link to three cognitive tests. In total, completion took 45-60 minutes. Participants were able to pause and return to the questionnaire at their choice.

Non-respondents and non-completers received an email reminder after two weeks. This was followed by a final reminder one more week later. Finally, individuals who had not completed the questionnaire or simply not responded to the mail were approached by phone one week after this last email.

First follow-up. After 7 months, students who fully participated at baseline were invited by email to participate in a short follow-up questionnaire consisting of 2 short questions. Non-respondents and non-completers received an email with a reminder after 2 weeks. Learning performance after 7 months was determined by collecting data from the exam registration office.

Second follow-up. After 14 months, students who fully participated at baseline were approached again via email to participate in the second follow-up questionnaire. Again an email reminder was sent after two weeks in case of non-response or non-completion and a phone call was made one week later if necessary. This time participants only filled out an online questionnaire which took 30-60 minutes of their time. Again participants were able to pause and return to the questionnaire at another chosen time. Learning performance after 14 months was determined by collecting data from the exam registration office. A time frame of 14 months was chosen, as students have 14 months to finish their course. After these 14 months, their course rights will expire and they have to pay extra to be able to finish the course.

\section{Participants}

Of the 4945 students who were approached, 2842 responded, and 2040 (1260 women, 780 men, $M_{\text {age }}=36.7$ years, age range: $18-80$ years) fully participated at baseline $(41.3 \%$ 
response rate). At the first follow-up, 1086 students completed the questionnaire (53.2\% response rate). At the second follow-up, 1195 students completed the questionnaire (58.6\% response rate).

\section{Measurements}

All original English items were translated from English into Dutch by a native Dutch speaker. To ensure the validity, these items were back-translated by a bilingual English/Dutch speaking person. Adjustments were made where necessary.

\section{Outcome variables.}

Learning performance. To compute learning performance, study progress information was gathered via the exam registration database of the OUNL after 14 months of studying. This data set consists of information on the course(s) the students are registered for. For each course, the start and end date, the obtained number of European Credits (ECs), the obtained grades, and the number of attempts of exams are known. The richness of this study progress information offers the possibility to compute various outcome variables (e.g., learning performance, drop out, student success).

Subjective study success. At baseline, students were asked to indicate their main motive to start a course at the OUNL. They could choose out of seven motives (e.g., "I want to better fulfil my current working position”; “I want to develop my (intellectual) capacities”), or give an open answer by choosing “other, namely...”. At second follow up, students were asked to what extent they achieved this goal and in the case they did not completely achieve it, if they still had the intention to achieve it.

\section{Biological variables.}

Sleep. Different aspects of sleep were investigated: sleep quality, chronotype (i.e., whether someone has a morning or evening preference), sleep duration, sleep schedule, sleepiness, and fatigue. 
Sleep quality. The quality of sleep was measured with the Pittsburgh Sleep Quality Index (PSQI; Buysse, Reynolds, Monk, Berman, \& Kupfer, 1989) which measures seven different categories regarding sleep quality.

Chronotype. Chronotype was measured using the Munich ChronoType Questionnaire (MCTQ; Roenneberg, Wirz-Justice, \& Merrow, 2003). It measures quantitative chronotype via reported sleep and wake times, and qualitative chronotype by one item rated on a scale ranging from extreme morning type (1) to extreme evening type (7).

Sleep duration. To measure sleep duration, items of the PSQI (Buysse et al., 1989) and items of the MCTQ (Roenneberg et al., 2003) were used.

Sleep schedule. Sleep schedule can be derived from items of the PSQI (Buysse et al., 1989) and MCTQ (Roenneberg et al., 2003) regarding sleep and wake times.

Sleepiness. Sleepiness was measured with the Epworth Sleepiness Scale (ESS; Johns, 1991) which estimates the chance to doze off or fall asleep during eight situations. Items were rated on a scale ranging from I would never fall asleep (1) to big chance to fall asleep (4).

Fatigue. To measure fatigue, the Fatigue Assessment Scale (FAS; Michielsen, De Vries, \& Van Heck, 2003) was used. Items were rated on a scale ranging from never (1) to always (5).

Nutrition. Different aspects of nutrition were measured: Fish intake, caffeine, breakfast, and supplements.

Fish intake. Fish intake was estimated by a validated short frequency scale (De Groot, Van Boxtel, Schiepers, Hornstra, \& Jolles, 2009) on how often they ate three different categories of fish based on content of docosahexaenoic acid (DHA). Items were rated on a scale ranging from never (1) to more than once a week (5).

Caffeine. To measure caffeine intake, participants were asked if and how much coffee, black and green tea, and caffeine containing energy drinks they consumed during an average 
day. Items were rated on a scale ranging from Less than 1 cup a day (1) to 5 or more cups a day (6) for coffee and tea, and Less than 1 can (240 ml) per day (1) to 5 or more cans per day (6).

Breakfast. To measure breakfast consumption and composition, participants were asked how many days per week they had breakfast, if they had breakfast during working days and non-working days (rated on a scale ranging from never (1) to always (5)), and what types of breakfast they consumed.

Food supplements. To measure food supplements intake, participants were asked whether they used supplements, and if so, what kind, brand, dose per pill and number of pills they used.

Physical activity. Physical activity was measured with the Short Questionnaire to ASsess Health-enhancing physical activity (SQUASH; Wendel-Vos, Schuit, Saris, \& Kromhout, 2003). Physical activity was measured as the accumulated product score of intensity of the activity multiplied by the minutes spent on the activity.

Sedentary behaviour. To measure sedentary behaviour, a questionnaire based on the SQUASH (Wendel-Vos et al., 2003) was developed. Sedentary behaviour was calculated by accumulating the minutes of sitting, sleeping, and lying per week.

\section{Psychological variables.}

Goal orientation. Goal orientation was measured with the Achievement Goal Questionnaire (AGQ; Elliot \& McGregor, 2001). This instrument consists of four subscales (mastery approach, mastery avoidance, performance approach, and performance avoidance) with three items each. Additionally, work avoidance orientation was measured with the work avoidance subscale (3 items) of a questionnaire developed by Harackiewicz, Durik, Barron, Linnenbrink-Garcia, and Tauer (2008). Items were rated on a scale ranging from totally disagree (1) to totally agree (7). 
Learning strategies. To measure learning strategies, part B of the Motivated Strategies for Learning Questionnaire (MSLQ; Pintrich, Smith, Garcia, \& McKeachie, 1993) was used. This instrument consists of nine subscales: rehearsal (4 items), elaboration (6 items), organization (4 items), critical thinking (5 items), metacognitive self-regulation (12 items), time and study environment management (8 items), effort regulation (4 items), peer learning (3 items), and help seeking (4 items). Items were rated on a scale ranging from totally disagree (1) to totally agree (7).

Self-efficacy. Self-efficacy was measured with Self-Efficacy for Learning and Performance, a subscale of part A of the MSLQ (Pintrich et al., 1993). These 8 items were rated on a scale ranging from totally disagree (1) to totally agree (7).

Perseverance. To measure perseverance, participants filled out the Grit Scale (Duckworth, Peterson, Matthews, \& Kelly, 2007). This scale comprised 12 items rated on a scale ranging from totally disagree (1) to totally agree (5).

Inter-role conflict. Inter-role conflict was measured by using the Work-Family-School Conflict Survey (Giancola, Grawitch, \& Borchert, 2009). This questionnaire included 14 items rated on a scale ranging from totally disagree (1) to totally agree (5) in two areas: Family-School Conflict (7 items) and Work-School Conflict (7 items).

Self-esteem. Rosenberg's Self-Esteem Scale was used to measure self-esteem (Rosenberg, 1965). It comprised 10 items rated on a scale from totally disagree (1) to totally agree (4) items.

Coping. To measure coping, the Utrechtse Coping Lijst (UCL; Schreurs, Van de Willige, Brosschot, Tellegen, \& Graus, 1993) was used. Participants responded to this 47-item questionnaire on a scale ranging from rarely or not at all (1) to very often (4). It consists of seven subscales, namely: active tackling (7 items), palliative reacting (8 items), 
avoiding (8 items), seeking social support (6 items), passive reacting (7 items), expression of emotions (3 items), and reassuring thoughts (5 items).

Stress. Participants were asked to indicate whether they had experienced stressful events during the previous year. This could both be positive (e.g., pregnancy, marriage) as well as negative (e.g., losing job, divorce) events. For each stressful (max. 5) event they had experienced they were asked to name what the event was (open answer) and how stressed they had felt lately because of the event on a scale ranging from rarely or not at all (1) to very much (5). They were then asked to indicate how stressed they currently felt on the same 5point scale.

Affect. Positive (PA) and negative affect (NA) were measured with the Positive and Negative Affect Schedule (PANAS; Watson, Clark, \& Tellegen, 1988). Participants were asked to indicate how they have felt in general in relation to 10 positive (e.g., enthusiastic, inspired) and 10 negative (e.g., afraid, hostile) emotions and feelings. Items were rated on a scale ranging from rarely or not at all (1) to very much (5).

Social support. Three types of social support were measured: financial, mental and practical social support. For each type, participants were asked to indicate how much support they received from one’s social circle (i.e., spouse, other family members, employer, colleagues, friends, university employers (e.g., study coach), and peer students). Items were rated on a scale ranging from not at all (1) to very much (5).

Test anxiety. To measure test anxiety, the 5-item Test anxiety subscale of the MSLQ (Pintrich et al., 1993) was used. Items were rated on a scale ranging from totally disagree (1) to totally agree (7).

Cognitive performance. To measure cognitive performance, participants were asked to complete three digitized cognitive tests: (1) the Trail Making Test (Army Individual Test Battery, 1944) as a measurement for shifting; (2) the Substitution Test (Smith, 1991) as a 
measurement for information processing speed; and (3) the N-back task (Lezak, Howieson, \& Loring, 2004) as a measurement for working memory and updating. Additionally, reaction times are recorded for all tests, which provides extra information about speed.

Background variables. Additional questions were asked to measure background variables relating to sex, age, nationality, mother tongue, body mass index, living situation, health-related quality of life (RAND-36; Van der Zee \& Sanderman, 1993), life satisfaction (SWLS; Diener, Emmons, Larsen \& Griffin, 1985), use of medication, use of alcohol, smoking and drugs habits, terms of employment, level of education, level of education of partner, expected average number of study hours per week, study motive, study goal, faculty of study, restrictions or (personal) circumstances that influence studying, and computer abilities.

\section{Ethical considerations}

The ethical review committee of the OUNL approved the study. At the start of the online questionnaire, participants had to actively tick a box in order to agree to an informed consent form. With this they declared that they were aware of personal data being gathered, gave permission to data being gathered and analyzed, and were aware that participation was fully voluntary and that they could withdraw at any time without explanation. Without ticking this box, participation was not possible.

\section{Limitations}

There are some limitations to this study. First, we exclusively used questionnaires to measure the biological and psychological factors. It is preferred to use a combination of subjective and objective measures to ensure reliability and validity of the measured variables, especially for the biological variables like physical activity (although research shows 
questionnaire data to be more reliable in adults compared to adolescents (Slootmaker, Schuit, Chinapaw, Seidell, \& Van Mechelen, 2009)). Within this population (i.e., students who study from their own home and live across the country) it is a logistical challenge to use objective measurements. Besides this, the ALOUD study is an exploratory research. Therefore, we chose to perform this research using an online questionnaire.

Second, because of the broad time frame of participation, there could be unintended differences between participants. At time of participation some students had not even started their course yet, while others were already at the end of the course.

Furthermore, it took students approximately 60 minutes to participate. To heighten the response rate, participants were given the opportunity to pause and return to the questionnaire at another chosen time. Because of this opportunity there might be a separation between participants who filled out the questionnaire at once and those who divided the questionnaire into more parts spread out over several weeks. In future research it is preferred to standardize the way of filling out the questionnaire.

Finally, we looked at learning performance after 14 months, i.e., duration of one course. It would be valuable to extend this time frame and to follow students throughout their study career at the OUNL.

\section{Acknowledgements}

We are grateful to Nick Daems and Jaap Murre of UvA NeuroTest BV for developing the digital cognitive tests, and Bogdan Boermans for his assistance with LimeSurvey. We would also like to thank Charlotte Wolff and Ine Verstappen for their contribution in the translation of the questionnaires, and Astrid Kokkelkorn for her assistance in generating the data from the exam registration database. 


\section{References}

Army Individual Test Battery (1944). Manual of Directions and Scoring. Washington, DC: War Department, Adjutant General’s Office.

Buysse, D.J., Reynolds, C.F., Monk, T.H., Berman, S.R., \& Kupfer, D.J. (1989). The Pittsburgh Sleep Quality Index (PSQI): A new instrument for psychiatric research and practice. Psychiatry Research, 28, 193-213. doi: 10.1016/0165-1781(89)90047-4

De Groot, R.H.M., Van Boxtel, M.P.J., Schiepers, O.L.G., Hornstra, G., \& Jolles, J. (2009). Age dependence of plasma phospholipid fatty acid levels: potential role of linoleic acid in the age-associated increase in docosahexaenoic acid and eicosapentaenoic acid concentrations. British Journal of Nutrition, 102, 1058-1064. doi:

10.1017/S0007114509359103

Diener, E., Emmons, R.A., Larsen, R.J., \& Griffin, S. (1985). The Satisfaction with Life Scale. Journal of Personality Assessment, 49, 71-75. doi: 10.1207/s15327752jpa4901_13

Duckworth, A.L., Peterson, C., Matthews, M.D., \& Kelly, D.R. (2007). Grit: Perseverance and passion for long-term goals. Journal of Personality and Social Psychology, 92, 1087-1101. doi: 10.1037/0022-3514.92.6.1087

Elliot, A.J., \& McGregor, H.A. (2001). A 2x2 achievement goal framework. Journal of Personality and Social Psychology, 80, 501-519. doi: 10.1O37//OO22-3514.80.3.501

Giancola, J.K., Grawitch, M.J., \& Borchert, D. (2009). Dealing with the stress of college: A model for adult students. Adult Education Quarterly, 59, 246-263. doi: $10.1177 / 0741713609331479$

Harackiewicz, J.M., Durik, A.M., Barron, K.E., Linnenbrink-Garcia, L.L., \& Tauer, J.M. (2008). The Role of Achievement Goals in the Development of Interest: Reciprocal 
Relations Between Achievement Goals, Interest, and Performance. Journal of Educational Psychology, 100, 105-122. doi: 10.1037/0022-0663.100.1.105

Howie, E.K., \& Pate, R.R. (2012). Physical activity and academic achievement in children: A historical perspective. Journal of Sport and Health Science, 1, 160-169. doi: 10.1016/j.jshs.2012.09.003

Johns, M.W. (1991). A new method for measuring daytime sleepiness: The Epworth Sleepiness Scale. Sleep, 14, 540-545.

Lezak, M.D., Howieson, D.B., \& Loring, D.W. (2004). Neuropsychological Assessment (4th ed.). New York: Oxford University Press.

Michielsen, H.J., De Vries, J., \& Van Heck, G.L. (2003). Psychometric qualities of a brief self-rated fatique measure: The Fatique Assessment Scale. Journal of Psychosomatic Research, 54, 345-352. doi: 10.1016/S0022-3999(02)00392-6

Pintrich, P.R., Smith, A.F., Garcia, T., \& McKeachie, W.J. (1993). Reliability and predictive validity of the Motivated Strategies for Learning Questionnaire (MSLQ). Educational and Psychological Measurement, 53, 801-813. doi: 10.1177/0013164493053003024

Richardson, M., Abraham, C., \& Bond, R. (2012). Psychological correlates of university students' academic performance: A systematic review and meta-analysis. Psychological Bulletin, 138, 353-387. doi: 10.1037/a0026838

Roenneberg, T., Wirz-Justice, A., \& Merrow, M. (2003). Life between clocks: Daily temporal patterns of human chronotypes. Journal of Biological Rhythms, 18, 80-90. doi: $10.1177 / 0748730402239679$

Rosenberg, M. (1965). Society and the adolescent self-image. Princeton, NJ: Princeton University Press.

Schreurs, P.J.G., Willige, G. van de, Brosschot, J.F., Tellegen, B., \& Graus, G.M.H. (1993). Handleiding Utrechtse Coping Lijst UCL (herziene versie). Lisse: Swets \& Zeitlinger. 
Slootmaker, S.M., Schuit, A.J., Chinapaw, M.J.M, Seidell, J.C., and Van Mechelen, W. (2009). Disagreement in physical activity assessed by accelerometer and self-report in subgroups of age, gender, education and weight status. International Journal of Behavioral Nutrition and Physical Activity, 6, 17. doi: 10.1186/1479-5868-6-17

Smith, A. (1991). Symbol Digit Modalities Test. Los Angeles: Western Psychological Services.

Van der Zee, K.I., \& Sanderman, R. (1993). Het meten van de algemene gezondheidstoestand met de RAND-36. Een handleiding. Groningen: Noordelijk Centrum voor Gezondheidsvraagstukken.

Watson, D., Clark, L.A., \& Tellegen, A. (1988). Development and validation of brief measures of positive and negative affect: The PANAS scales. Journal of Personality and Social Psychology, 54, 1063-1070. doi: 10.1037/0022-3514.54.6.1063

Wendel-Vos, G., Schuit, A., Saris, W.H.M., \& Kromhout, D. (2003). Reproducibility and relative validity of the Short Questionnaire to Assess Health-enhancing physical activity. Journal of Clinical Epidemiology, 56, 1163-1169. doi: 10.1016/S08954356(03)00220-8

Wigfield, A., \& Cambria, J. (2010). Students' achievement values, goal orientations, and interest: Definitions, development, and relations to achievement outcomes. Developmental Review, 30, 1-5. doi: 10.1016/j.dr.2009.12.001 